\title{
Trial by fire: Testing the paleolongitude of Pangea of competing reference frames with the African LLSVP
}

\author{
RosS N. MitCHELL ${ }^{12}$, LEI WU ${ }^{2}$, J. BRENDAN MURPHY ${ }^{23}$, \\ ZHENG-XIANG LI ${ }^{2}$
}

${ }^{1}$ State Key Laboratory of Lithospheric Evolution, Institute of Geology and Geophysics, Chinese Academy of Sciences, Beijing, China, ross.mitchell@mail.iggcas.ac.cn

${ }^{2}$ Earth Dynamics Research Group, The Institute for Geoscience Research (TIGeR), School of Earth and Planetary Sciences, Curtin University, GPO Box U1987, Perth,WA, Australia, lei.wu@curtin.edu.au, z.li@exchange.curtin.edu.au

${ }^{3}$ Department of Earth Sciences, St. Francis Xavier University, Antigonish, Nova Scotia, Canada, bmurphy@stfx.ca

Paleogeography can be reconstructed using various crustor mantle-based reference frames that make fundamentally different assumptions. The various reconstruction models differ significantly in continental paleolongitude, but it has been difficult to assess which models are more valid. We suggest here a "LLSVP test", where an assumed correlation between present-day large low velocity shear-wave provinces and the paleogeography of supercontinent Pangea at breakup ca. 200 million years ago can be used to assess the relative accuracy of published reconstructions. Closest correlations between continental paleolongitude and the African LLSVP are achieved with mantle-based reference frames (moving hotspots and true polar wander), whereas shallower crustbased reference frames (paleomagnetic Euler poles and slabs) are shown to be invalid. The relative success of mantle-based frames, and thus the importance of the depth of reference frame, supports the notion that mantle convection is largely vertical compared to the horizontal plate motion of tectonics. 